FACULDADE DE MEDICINA DA UNIVERSIDADE DE SÃO PAULO

Departamento de Anatomia Patologica - Diretor: Prof. DR. Ludgero da CUnha Motta

\title{
O FATOR CONSTITUCIONAL DO CANCER ESTUDADO NO RATO PELO METODO DA PARABIOSE
}

\author{
CARLO FOÁ e UBIRAJARA MONTEIRO
}

O desenvolvimento de tumores malignos, como aliás de qualquer processo patologico, está condicionado a uma constelação de fatôres, sendo de notar que alguns deles, devido á sua aparente predominancia, costumamos chamal-os dè fatôres causais. Assim se fala do 3,4benzopirene, como de uma "causa" de cancer; e não se tem tomado na devida consideração o fáto deste fatôr cancerogeno, estar, por sua vez, condicionado a fatôres diferentes, que podem ser resumidos nạ palavra: predisposição constitucional, disposição de especie, de individuo e de tecido. Tanto isso é verdade que, no coelho e no rato, o cancer cutaneo produzido pelo benzopirene desenvolve-se muito menos do que no camondongo, e que existem regiões da pele ou das mucosas onde a reacção se faz mais facil e rapida do que em outras, sob a aç̧ão cancerogenica do hidrocarbureto.

A variação individual da resposta é ainda maior frente a outros fatôres oncogenicos, como o aminazotoluol, cuja acção cancerogenica sobre o figado aparece muito variavel e, talvez, condicionada á alimentação e ás reservas de glicogenio e de vitaminas presentes naquele orgão. A degeneração cancerosa do papiloma de Shope, no coelho, depende com toda a certesa, de outros fatôres irritantes accessorios, que colaboram com a virus-proteina para transformar a neoformação benigna em maligna. Portanto, não ha duvida de que entre os fatôres que condicionam ou inhibem o desenvolvimento do tumor maligno, predomina o fatôr constitucional genetico.

Com efeito, a genetica moderna, começou a penetrar na oncologia experimental, seja no estudo da herança de tumores expontaneos em certas especies animais - como o cancer da mama, na femea do camondongo - seja orientando pesquisas sobre a receptividade neoplastica a estimulos cancerogenicos de linhagens murinas selecionadas e puras, isto é, omozigotas para o maior numero possivel de caractéres. Foram, assim, selecionadas linhagens murinas, nas quais a incidencia do cancer mamario excede a $70 \%$, e outras que são pratica- 
mente'imunes ao tumor. Altamente interessante é a observação de Kreyberg (1) em que o complexo dos fatôres geneticos que favorecem. o aparecimento do cancer expontaneo da mama, não são os mesmos que condicionam a maior receptividade á acção oncogenica do alcatrão. Parece, portanto, não se poder falar em uma generica diatese oncoplastica, mas de fatôres de predisposição diversos, frente a diferentes fatôres cancerogenicos, e talvez, dissociados e presentes em cromosomas outros.

As pesquisas que melhor procuraram analisar a receptividade oncoplastica sobre bases constitucionais geneticas são as de Dobrovolkaia, Zavadkaia e Adamova (2). Tendo á sua disposição linhagens murinas indenes de cancer expontaneo, as autoras russas trataram um grande numero de animais dessas linhagens: (até 1547) com alcatrão ou com 1, 2, 5, 6 - dibenzoantracene, ou com radon, ou com uma espiroqueta (Sodoku). A espiroqueta não deu resultado, mas os outros fatôres deram resultados omogeneos, isto é, o aparecimento de epitelioma, quando aplicados externamente na pele, e de sarcoma quando injetad́os em baixo da'pele. Nunca apareceram tumores na mama ou em outras glandulas, a não ser em linhagens que continham elementos de uma outra, com ocorrencia de tumores expontaneos. Pode-se, portanto, afirmar que, emquanto o tumor expontaneo da mama é condicionado a fatôres constitucionais, os tumores provocados por hidrocarburetos são estrictamente dependentes do fatôr externo. E, todavia, não se póde negar que, tambem, esta generica reacção ao fatôr externo, não seja, em alguns aspectos, dependentes do terreno constitucional. As autoras russas verificaram que nas linhagens murinas indenes de cancer, existem tendencias a doenças diversas: lesões hepaticas, diatese hemorragica, hiperplasia tireoideana, linfoadenopatia, dermatose. Pois bem, essas disposições patologicas diferentes determinaram algumas diferenças na reação oncoplastica ao hidrocarbureto, com o aparecimento da alopécia total nas familias com tendencia á dermatose e de quadros leucemicos ou esplenomegalicos nas com tendencia á linfoadenopatia.

As referidas autoras estudaram tambem a acção dos hidrocarburetos e do radon em familias murinas com alta incidencia de cancer mamario $(53,5 \%)$ e os resultados, em 1184 camondongos foram complexos e de não facil interpretação. $O$ estimulo local provocou o desenvolvimento habitual de tumores in situ, mas não sómente não facilitou o aparecimento do cancer racial expontaneo da mama, como frequentemente o diminuiu! Desta observạção surgiu a hipotese de que os fatôres cancerogenicos externos sejam talvez capazes de substituir uma nova fórma de tumor local, pela forma tumoral que teria aparecido expontaneamente por forças geneticas e constitucionais.

- Este problema foi lançado tambem por Cramer (3), baseando-se em verificações estatisticas no homem. Quando n'uma povoação a incidencia do cancer prevalece em um dado orgão, em virtude de causas do ambiente, profissionais ou parasitarias, nessa mesma povoação a incidencia de tumores em outroṣ orgãos diminue. Um feno- 
meno analogo se verifica nos dois sexos, considerados como raças cromosomicamente diferentes: a frequencia do cancer do sistema genito-mamario ná mulher não implica em uma maior tendencia oncoplastica geral, sendo compensada pela menor frequencia, em relação ao homem, do cancer de outros orgãos, particularmente da boca, do esofago e do estomago. Mas, as conclusões de dados estatisticos devem sér feitas com cuidado porque elas podem ser diferentemente interpretadas. Assim, Dormanns (4) observa que a predominancia do cancer em um orgão provoca o desaparecimento de individuos antes de que, possivelmente, neles se desenvolvam tumores em outros orgãos, tanto mais que, a maxima incidencia de tumores produz-se nos diversos orgãos, em edades diferentes.

Quando se fala em fatôres hereditarios, faz-se referencia á caractéres ligados a unidades materiais presentes nos cromosomas, isto é, aos gêns hereditarios. Póde-se, portanto, afirmar que existem gêns responsaveis pela reação oncoplastica á fatôres cancerogenicos cu, mais ainda, que existem anormalidades do sistema dos gêns, das quais resulta o caracter hereditario do aparecimento de tumores malignos, como certos melanomas observados por Stark, na Drosophila (5), e o glioma da retina, no homem. Além dos fatôres cromosomicos foram evidenciados fatôres extra-cromosomicos na transmissão hereditaria do cancer. (Little (6), Korteweg (7), Mac Dowell (8). Assim, o cancer da mama e a leucemia dos camondongos (definidos como forma neoplasica sistemica), seguem as leis da herança matroclina, cabendo prevalentemente ás femeas a transmissão hereditaria da doença.

Cruzando-se femeas de linhagem oncoplasticas com machos de linhagens imunes, obtem-se uma decendencia cancerosa muito mais numerosa do que cruzando femeas de linhagens imunes com machos de linhagens oncoplasticas. Como a herança cromosomica implica em igual importancia no patrimonio genetico masculino e feminino, deve-se concluir que na herança matroclina manifesta-se uma influencia extracromosomica, na qual prevalece o citoplasma ovular. (A. Kühn (9)

Para fornecer a prova de que o fator da alta incidencia do cancer da mama é ligado ao citoplasma do ovo, precisava fazer variar em grupos de individuos a quantidade de cromatina derivada da linhagem cancerosa e da linhagem sã, mantendo constante a origem do citoplasma ovular, ou vice-versa. Murray e Little, por meio de cruzamentos oportunamente estudados, obtiveram quatro grupos de individuos:

A) com $75 \%$ de cromatina da linhagem cancerosa e o citoplasma da linhagem sã;

B) com $75 \%$ de cromatina e tambem o citoplasma, da linhagem cancerosa;

C) com $75 \%$ de cromatina e tambem o citoplasma da linhagem sã ; 
D) com $75 \%$ de cromatinà dà linhagem sã e o citoplasma da linhagem cancerosa.

Pois bem - a incidencia percentual do tumor foi a seguinte:

em A) $-7,14 \%$
em B) $-53,4 \%$
em C) $-6 \%$
em D) $-50,86 \%$

o que demonstra claramente que a incidencia do tumor é ligada ao fato de o citoplasma derivar ou não de mãe de linhagem cancerosa.

Esta doutrina da transmissão hereditaria extracromosomica pareceu sofrer seria critica por parte de Bitner (10), segundo o qual as camondongas nascidas de mães de linhagem cancerosa só passam a adoecer quando mamaram o leite materno. O leite veicularia portanto um agente ainda desconhecido, causador da futura canceração da glandula mamaria. Segundo a nossa opiniăo, a descoberta deste fator oncogenico externo, que aliás se acha presente não só no leite mas tambem em diferentes orgãos das mães de linhagem cancerosa, não exclue a existencia do fator genetico extracromosonico.

Verificou de fato o proprio Bitner que nas camondongas de linhagem isenta de cancer, o aleitamento por amas de linhagem cancerosa não faz aparecer o tumor. Falta nelas o fator genetico constitucional necessario ao aparecimento do tumor. Existiria portanto um "complexo cancerogenico" para cuja integração deveria coexistir um fator genetico constitucional, o fator lacteo, e um fator hormonal. Thales Martins (11) encara este ultimo na sua verdadeira luz, quanda admite que os hormonios ovarianos não teem neste caso papel cancerogenico, só constituindo o fator necessario à morfogenese da glandula mamaria, o que é base indispensavel para, na propria glandula, se encontrarem sucessivamente as condições do desenvolvimento do cancer.

Muito se fala em alterações precancerosas, sem que se possa prever o gráu de maior ou menor probabilidade que elas teem de gerar o tumor maligno. Frequentemente o fatôr constitucional influe em determinar a intensidade de processos proliferativos, devidos a um estimulo qualquer, processos que, num segundo tempo, podem assumir o caracter de malignidade. Consideramos, por exemplo, o xeroderma pigmentosum; consiste esta doença numa hipersensibilidade fótica da pele, devido a fatôres hereditarios constituidos por gêns de efeito subletal. Desde que a criança predisposta esteja em exposição á luz solar, aparece uma série de processos irritativos da pele, de naturesa flogistica, com longas fases de restauração, durante as quais, frequentemente, ha logar o desenvolvimento de canceres multiplos da pele. Neste caso não se póde dizer que o proprio cancer seja constitucional ou hereditario, mas o é a hipersensibilidade fótica da pele, que conduz á longa odisséa das reações inflamatorias, sobre as quais implanta-se o cancer. Do mesmo modo, o cancer intestinal que se manifesta na polipose hereditaria do intestino, não é por si mesmo 
nem constitucional e nem hereditario; o é a polipóse, que condiciona secundariamente o aparecimento do cancer.

O problema da herança do cancer deve ser encarado mais como problema da transmissão hereditaria da tendencia a adoecer de tumor maligno, que da propria transmissão do tumor. Encarando-o desta forma, admite-se que o fator hereditario consiste na capacidade ou não de reagir ao estimulo oncogenico, considerado por sua vez como fator necessario ao desencadeamento da regeneração atipica. A dificuldade principal no estudo da genetica dos tumores humanos está no fato de se encontrarem entre os individuos considerados "sãos", tambem os que, mesmo não manifestando a doença, podem transmiti-la à descendencia (eterozigotes) e os que, sendo homozigotes para o carater neoplastico, não tiveram a oportunidade de manifestar o tumor só por falta do estimulo oncogenico.

Alem disso, se se admite que o aparecimento do tumor seja condicionado a dois fatores, um hereditario e constitucional, o outro causal, para estudar o primeiro deveria ser mantido constante o segundo, o que se procura fazer na oncologia experimental. Mas um ponto que nos parece essencial é o seguinte. Considera-se geralmente, do ponto de vista genetico, como individuo são o que não adoeceu de cancer, e "canceroso", o que tinha as condições constitucionais para reagir positivamente ao estimulo oncogenico. Parece-nos importante considerar como tipo geneticamente eficiente o que não adoece de cancer por ter em si mesmo forças que o impedem; isto é, por ser positivamente refratario ao estimulo oncogenico. Existem de fato não somente as linhagens oncorreceptivas, como tambem as oncorresistentes ou oncorrefratarias, para não dizer oncoimunes, o que sugeriria uma interpretação antecipada da oncorresistencia. O jogo dos fatores hereditarios não deve ser portanto limitado aos alelomorfos: canceroso (ou oncorreceptivo) e são (não receptivo), mas tem que ser considerado tambem o fator da "oncorresistencia", que vai alem da simples falta de receptividade.

Os fatores hereditarios constitucionais seriam portanto dois, opostos: a oncorreceptividade e a oncorrefratariedade, ao reagir a estimulos oncogenicos.

Acreditamos que as duas propriedades geneticas, e portanto constitucionais, não representam fatores absolutos, podendo talvez ser encontradas receptividade ou refratariedade relativas à qualidade dos estimulos oncogenicos: maximas e especificas para os tumores que nos parecem "espontaneos", por não idenficarmos o fator oncogenico - imediato; minimas diante de estimulos oncogenicos aspecificos e violentos, como são os hidrocarburetos cancerogenos.

Poder-se-ia esperar que o problema da herança oncogena teria sido esclarecido pelos casos dos gemeos monocoriais que, derivando do mesmo zigote, possuem patrimonio hereditario identico. Na hipotese de que o tumor seja unicamente devido a fatores hereditarios, quando ele aparecesse num. dos gemeos, deveria surgir tambem no outro, em sede identica, o que, aliás, foi observado em alguns casos. 
Halliclay-Croon (1913) verificou o contemporaneo aparecimento de cancer uterino em duas gemeas monocoriais; Hedinger (1915) cita o caso de duas gemeas monocoriais nas quais um carcinoma primitivo do figado apareceu na idade de 71 e 77 anos; Burkard (1922) lembra o caso de duas $\mathrm{g}$. $\mathrm{m}$. nas quais apareceu a 21 anos de idade um fibroadenoma da mama esquerda. Dameshek, Saitz e Arbor (1929) observaram o caso de dois g. m. falecidos ambos a 56 anos de idade por leucemia linfatica. Numerosos são os casos analogos registados na literatura, mas não menos numerosos são os casos nos quais o tumor apareceu nos dois g. m. em sede diferente, ou apareceu num só e não no outro.

$\mathrm{O}$ fáto de não terem os gemeos monochoriais a mesma incidencia do cancer, a não ser em numero limitado de casos, póde ser interpretado admitindo uma individualidade constitucional tão especifica, que supera até a identidade do patrimonio hereditario dos mesmos gemeos. Mas, pode-se, ao contrario, admitir que a constituição individual não seja o fatôr predominante, e que o sejam fatôres oncogenicos externos, cuja acção póde se manifestar em um e não no outro gemeo. Seja como fôr, não ha duvida de que o fatôr constitucional, devido á herança biologica, representa, na maioria dos casos, um elemento indispensavel para o desenvolvimento do tumor maligno ou para determinar o aparecimento de lesões predisponentes a successivas transformações de naturesa maligna.

A prova experimental mais certa da importancia do fator constitucional no desenvolvimento do cancer, consiste na existencia de linhagens de ratos e de camondongos nas quais não sómente não aparecem, por muitas gerações, tumores expontaneos, como tambem não pegam tumores enxertados; ao passo que, em outras linhagens o tumor enxertado pega com facilidade na grande maioria dos individuos. Esta "imunidade" natural não encontrou, por emquanto, uma explicação satisfatoria. Será ela devido aos humores do organismo? ou aos tecidos? $\mathrm{O}$ fato do sôro de animais canceroresistentes não proteger os receptores contra o cancer enxertado, não é argumento suficiente para se negar a existencia de principios ou propriedades antitumorais no sangue do animál resistente. Talvez, para que estas propriedades se manifestem, se exijam grande massa de sôro e um longo praso de acção, condições estas bem dificeis de serem realisadas, a não ser pelo método que fórma o objecto da presente pesquisa: a parabiose.

Consiste este metodo, como é sabido, em unir dois animais pelos flancos, formando uma soldadura entre as paredes toraxicas, peritoneais, musculares e cutaneas. Assim que se fórma uma ponte destas paredes, entre os dois animais, e que as duas cavidades abdominais se comuniquem amplamente, formando entre'si uma unica. Além da comunicação humoral estabelecida entre os dois animais pelo liquido peritoneal, irão gradativamente abrindo-se vias linfaticas e sanguiferas comuns na ponte muscular e cutanea que une os parabiontes. 
Depois de um certo tempo, eles deveriam constituir um unico individuo, do ponto de vista humoral.

Numerosas pesquisas foram feitas no sentido de estudar as interrelações humorais e endocrinas entre os parabiontes (Sauerbruch, Morpurgo, Thales Martins), chegando-se á demonstração certa do intercambio de hormonios e de substancias extranhas ministradas a um só dos parabiontes. Mas, a existencia deste intercambio e de reciprocas influencias endocrinas entre os parabiontes, ainda não significa que eles cheguem a constituir verdadeiramente um individuo só, do ponto de vista da individualidade constitucional.

- O problema pode ser estudado por metodos diferentes, entre os quais escolhemos os dois seguintes, baseados sobre as seguintes perguntas :

a) o enxerto de tecidos ou organs de um para o outro parabionte terá o valor e fornecerá os resultados dos enxertos homo ou autoplasticos?

b) um tumor maligno, expontaneo ou experimental, afetando um dos parabiontes, afetará necessariamente tambem o outro, ou os dois individuos, conservarão as propriedades constitucionais de resistencia ou de receptividade pelo dado tumor?

Deixando para outra publicação os resultados da primeira pesquisa, relataremos aqui o que se refere á segunda.

Temos que lembrar um antigo trabalho de B. Morpurgo, encarando a problema sob o mesmo ponto de vista. Infelizmente não nos foi possivel ler o referido trabalho no original, e devemos a uma recente cartá pessoal do proprio Autor o conhecimento dessas interessantissimas pesquisas. Dispunha o Prof. Morpurgo de duas linhagens de ratos, das quais uma praticamente refrataria ao enxerto de um sarcoma, e a outra muito sensivel, na qual o sarcoma enxertado pegava em 80 a $100 \%$ dos individuos. Morpurgo operava a parabiose entre ratos pertencentes ás duas linhagens e, depois de um certo tempo, procedia ao enxerto do sarcoma de duas maneiras diferentes: enxertando uma fatia do tumor em baixo da pele ao longo da cicatriz dorsal, ou colocando-a a cavalo na cicatriz ventral da celostomia, de maneira que uma metade da fatia pendesse na cavidade abdominal de um dos parabiontes, e a outra, na cavidade abdominal do outro. $O$ resultado dessas experiencias foi muito evidente: o tumor enxertado pegou e se desenvolveu só no lado do animal receptivo, atrofiando-se no parabionte refratario. Como não dispusessemos de linhagem de ratos refratarios ou receptivos ao sarcoma conservado ha anos no Departamento de Anatomia Patologica, em successivos transplantes, não nos foi possivel repetir a interessante experiencia de Morpurgo.

Quando o tumor enxertado em baixo da pele, ao longo da cica-: triz dorsal, de modo simetrico entre os parabiontes, o seu desenvolvimento se produz tambem simetricamente, ocupando cerca do mesmo volume, em relação aos dois animais, (Fig. 1) 


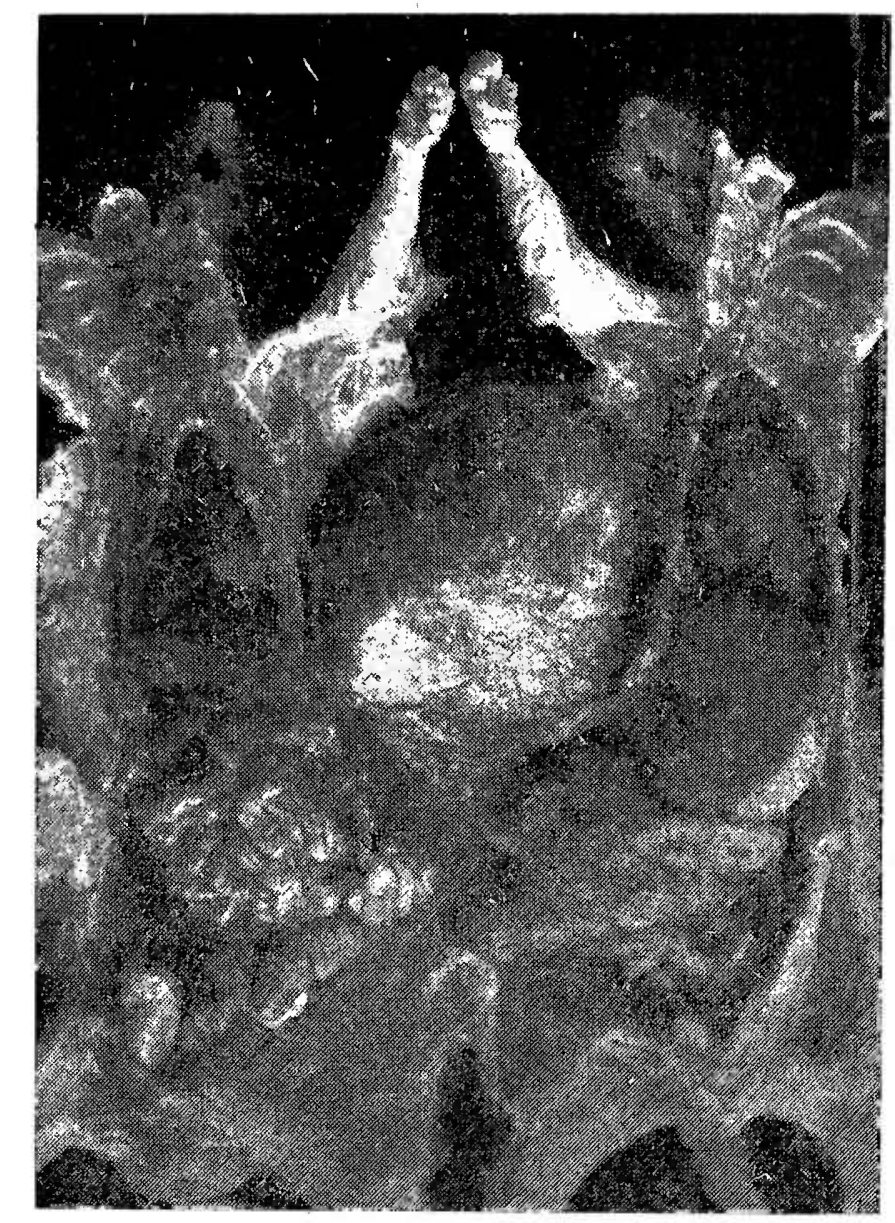

FIG. 1

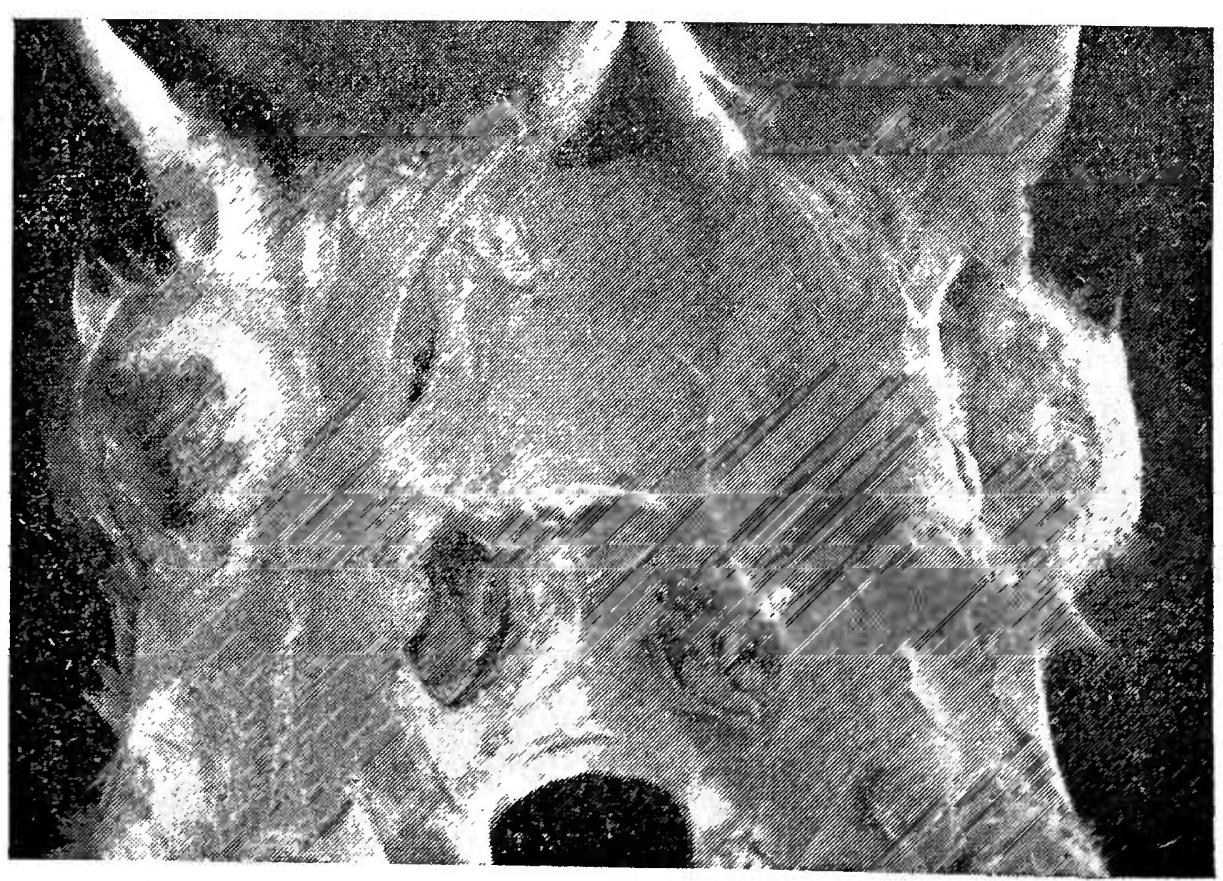

FIG. 2 
Enxertando dois pequenos fragmentos, praticamente do mesmo volume, em baixo da pele dos flancos externos dos parabiontes, os dois sarcomas crescem paralelamente. (Fig. 2) Tudo isso, entretanto, não tem referencia alguma com o assunto da constituição individual; apenas tem o valor de demonstrar que, quando os parabiontes pertencem a raças receptivas, o fáto de serem unidos em parabiose em nada inflúe na péga e no desenvolvimento do tumor nos dois animais. Isso não admira, porem, está em contradição com a afirmativa de Albrecht, o qual diz que a parabiose impede o desenvolvimento dos tumores enxertados. Ficamos com a opinião de Morpurgo, quảndo ele afirma que a aparente contradição depende de os parabiontes se encontrarem ou não "em perfeito equilibrio de nu. trição. Quando um dos dois - o que frequentemente acontece se atrofia, emquanto o outro aumenta de peso ou mantem o pesa primitivo, no parabionte atrofiado o tumor, ou não péga, ou quando já desenvolvido, regride. Este fenomeno, aliás, se verifica tambem em animal isolado, observando-se que o tumor enxertado regride quando aparecem condições de desnutrição geral.

Devemos a uma observação fortuita, a demonstração mais interessante do quanto nos não teria sido possivel realisar, de outro modo dada a ausencia de raças refratarias ao sarcoma do qual dispunhamos. Um casal de ratos mestiços, femeas pertencentes a familias diferentes e unidas em parabiose desde muito jovens, viveram um ano em perfeito equilibrio de nutrição e sem que se verificasse o menor incidente, com o aumento progressivo e notavel de peso até a edade adulta. Um dia, esses animais foram encontrados mortos, sem que nos dias precedentes fossem notados sintomas de estarem doentes. Á autopsia demonstrou que um dos parabiontes apresentava um tumor generalisado, com metastases multiplas em todos os orgãos abdominais e até no pulmão. (Fig. 3) As alças intestinaís estavam coladas pelas metastases mesentericas, e na cavidade abdominal comum aos dois animais achava-se um derrame hemorragico no qual, além -das celulas sanguineas, existiam celulas de descamação do peritoneo e celulas tumorais. A superficie do peritoneo parietal do parabionte canceroso estava inteiramente avermelhada pela invasão sanguinea de seus vasos dilatados. Mas, o que mais chamava a atenção éra o fato de faltar ao outro parabionte qualquer sinal de tumor, apresentando a superficie do peritoneo parietal, assim como do viceral, um aspécto perfeitamente transludido e normal, sem a menor vasodilatação. Os dois diferentes aspéctos do peritoneo estavam nitidamente delimitados ao longo da linha cicatricial do peritoneo, no sentido longitudinal da soldadura dos pärabiontes.

O exame histologico do tumor, feito pelo dr. Paulo Tibiriça, revelou o diagnostico de angioendotelioma, e sobre esse caso o mesmo dr. Tibiriça publicou um trabalho encarando-o sob o aspecto da possivel etiologia do tumor. (12).

Achamos que dificilmente se poderia encontrar um caso de tão grande evidencia como o nosso, para demonstrar a estricta individua- 
lidade constitucional e sua influencia na reação do organismo á inva. são de um tumor tão maligno, como o que expontaneamente apareceu em um dos nossos parabiontes, respeitando completamente o outro. Não sómente neste ultimo não houve a minima invasão tumoral, mas até a reação peritoneal inflamatoriạ, da qual originou o derrame hemorragico, se mostrou nitidamente delimitada ao folheto peritoneal

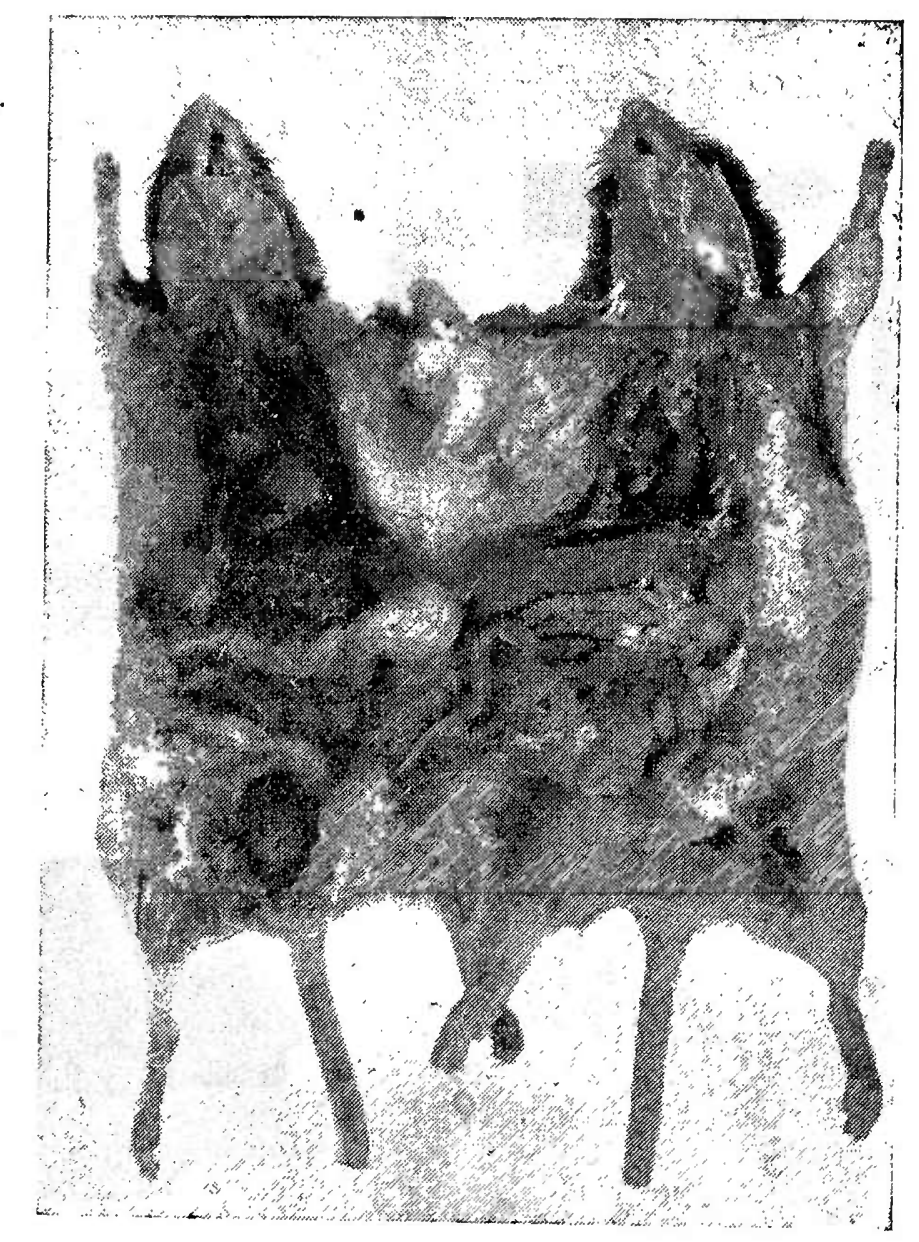

FIG. 3

do animal doente, enquanto que o derrame invadio todo o espaço da cavidade abdominal, comum aos parabiontes.

A longa convivencia em comunhão humoral, em nada modificou a constituição individual no que diz respeito á refratariedade ou receptividade oncoplastica; cada um dos parabiontes guardou a sua propria individualidade e com a oposição nitida de ambas. O organismo refratario não permitiu que nele se implantasse uma celula tumoral, capaz de desenvolver o tumor e nem deixou que nele vivesse ou se desenvolvesse qualquer agente eventual cancerogeno.

Devemos, pois, concluir que a refratariedade ou imunidade, seja humoral ou tecidual em relação ao tumor maligno, constitue uma propriedade fundamental do organismo, que o faz resistir á invasão do 
tumor, mesmo quando se verifiquem as condições mais oportunas, como são as criadas por uma parabiose de longa duração. O fato de viverem os parabiontes em continuo intercambio humoral não constitue, do ponto de vista da constituição, um individuo unico, guardando cada um deles a mais especifica individualidade organica, dados os fatôres imutaveis hereditarios e constitucionais.

Isto não exclue, entretanto, a possibilidade de se obter um enfraquecimento qualquer da refratariedade constitucional do rato oncoresistente, criando nele aquelle "periodo sensivel" que precede e condiciona o aparecimento da "disposição geral aos tumores" (FischerWasels e Büngeler). (13) Pòr meio de substancias toxicas, ou dotadas de acção cancerogenica ou ainda de fatôres fisico-irritantes, tãis como as radiações ou queimaduras, esplenectomia ou pelo bloqueio do S. R. E., conseguio-se transformar processos proliferativos benignos em neoplasias malignas, facilitando, em alguns casos, a formação de metastases.

Pesquisas semelhantes seria talvez interessante repetir em parabiontes portadores de tumores experimentais, poem julgamos que elas pouco acrecentariam aos resultados obtidos em individuos isolados.

O fenomeno que nos foi dado observar e que aqui descrevemos, isto é, o aparecimento de um tumor maligno expontaneo em um dos parabiontes, sendo o companheiro refratario, representa uma eventualidade tão casual e rara, que não se presta a tentativas feitas com o intuito de enfraquecer a refratariedade constitucional do parabionte imune. De qualquer modo, em nada poderia este resultado modificar o valor do caso que acabamos de ilustrar, e que demonstra a influencia fundamental da constituição, em adoecer de cancer ou em resistir ao tumor.

\section{B I B L I O G R A F I A}

1 - KREYBERg - (Am. J. of Cancer - 24. 554 - 1935).

2 - Dobrovolinaia, Zavadskaia, Adamova - Bull. Ass. Franc. pour l'étude du Cancer -27, n. $4-1938$ e 28, n. 1 - 1939).

3 - Cramer - (Congr. Int. du Cancer - Bruxelles 1936).

4 - Dormanns - (Congr. Int. du Cacer - Bruxelles 1936).

5 - Stark - Amer. J. Cancer - 31. 253. 1937.

6 - Lititle - Am. J. Cancer - 27. 55. 1936.

7 - KoRTEWEg - Lewenhoek Vereinig - Amsterdam 1935.

8- Mac Dowell - Am. J. Cancer - 26. 85. 1936.

$9-\mathrm{A}$. $\mathrm{KÜHN}-$ Z. f. Züchtungskunde $-12.443-1937$.

10 - J. Bitner - Am. J. Cancer - 30. 530. 1937 e 36. 44. 1939 - J. of the Nat. Cancer Inst. 1. 155. 1940.

11 - Thales Martins - O Hospital - XXII. 339. 1942.

12 - P. Q. T. TibiriçÁ - Anais da Fac. de Med. da Univ. de S. Paulo 1941. IÎ. 641.

13 - W. Büngeler e F. L. Alayon - Arq. Cir. Clin. e Exp. - II, 1938 n. 2. 

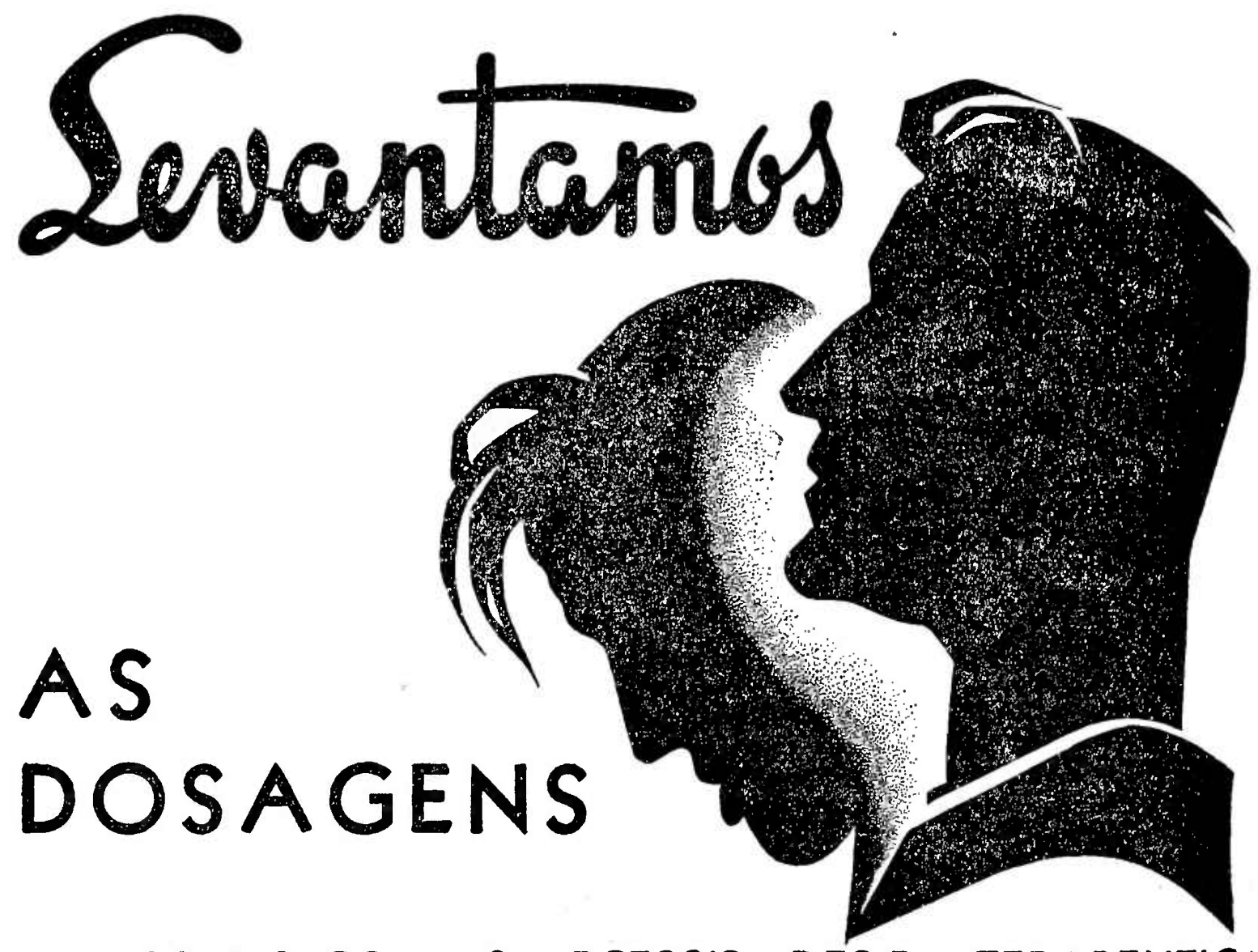

DE ACORDO COM AS NECESSIDADES DA TERAPEUTICA

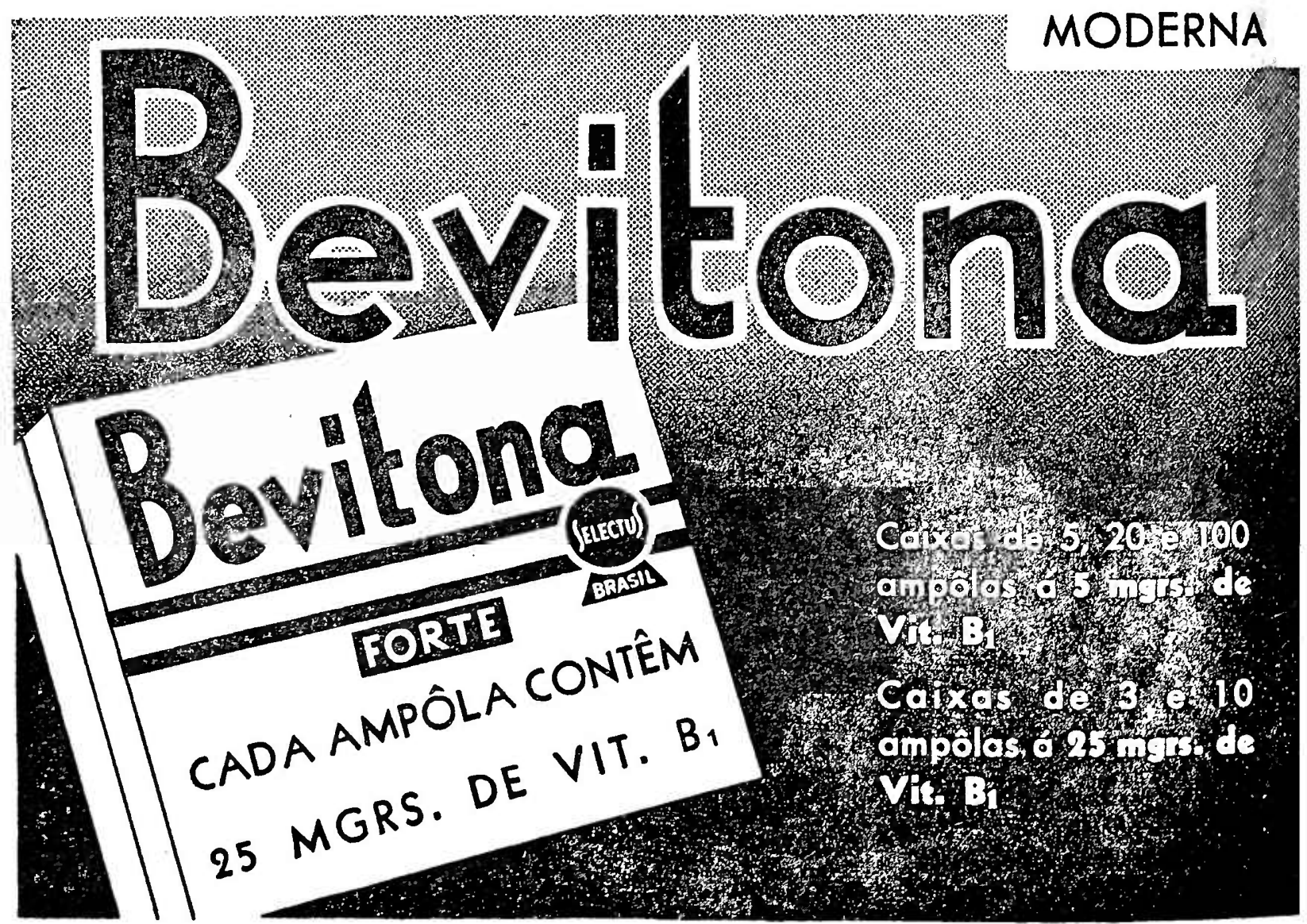

